\title{
A self-sustainable winery, an advanced passive building and remote monitoring of environments in wineries
}

\author{
Roger Boulton \\ Department of Viticulture and Enology, University of California, Davis, CA, USA
}

\begin{abstract}
The self-sustainable winery was conceived in 2006 and the intention was to create a building and its related utility systems that would operate independently from the energy and water grids and to eliminate hydrocarbon fuels from its operation, capture and sequester the carbon dioxide from its fermentations and create a zero carbon footprint facility. The winery was the highest scoring LEED building at any university when it was completed and the first LEED Platinum Winery in the USA. The adjacent Jess Jackson sustainable winery building is a highly passive research and utility space that will house the advanced energy and water systems that make this off-grid performance possible. Together these buildings will operate every daily in energy and water positive modes and at capacities, which exceed the demands even during the harvest season. The data system incorporated into these buildings for one hundred and fifty research fermentors, fourteen teaching fermentors will also monitor all energy, water and building activities in a secure, cloud-based software system that supports both web and handheld access, with the potential for bidirectional date and control functions. This data network has been extended to include real time monitoring of temperature, humidity, carbon dioxide and volatile organic compounds in five produc-
\end{abstract}

Correspondence: Roger Boulton, Department of Viticulture and Enology, University of California, Davis, CA, USA.

E-mail: rbboulton@ucdavis.edu

Key words: Winery design; self-sustainability; carbon dioxide reduction.

Acknowledgements: the author gratefully acknowledges the support of grant from the Sloan Foundation, a fellowship from the TJ Rodgers Foundation and the Stephen Sinclair Scott Endowment. My thanks also to Dr. Alberto Barbaresi and Professor Patrizia Tassinari at the University of Bologna, Italy and the Organizing Committee of the Smart Rural Buildings: Food Security, Safety and Sustainability international conference of the 2nd section of the Italian Association of Agricultural Engineering held at SAIE 2016.

Received for publication: 8 June 2017.

Accepted for publication: 28 July 2017.

CC Copyright R. Boulton, 2017

Licensee PAGEPress, Italy

Journal of Agricultural Engineering 2017; XLVIII(s1):735

doi:10.4081/jae.2017.735

This article is distributed under the terms of the Creative Commons Attribution Noncommercial License (by-nc 4.0) which permits any noncommercial use, distribution, and reproduction in any medium, provided the original author(s) and source are credited. tion areas within two commercial winery sites and two creamery facilities, located more than $100 \mathrm{~km}$ from Davis. This now provides an example of a distributed dynamic network for the monitoring of the built environment in remote commercial food and wine facilities.

\section{Introduction}

The design of agricultural buildings, in particular food processing buildings, differs from standard buildings in a number of ways.

The main difference can be found in the specific needs to guarantee food safety and quality. The food aspect, in fact, requires levels of cleanliness often associated with daily cleaning and moisture, the seasonal nature of harvesting of fruits and vegetables, the humidity required to prevent drying, the maintenance of certain temperatures for microbial activity or aging, the emission of fermentation vapor and the movement of people and product from room to room during the production stages (Boulton et al., 1998). Moreover, processed foods can differ also for the period of production. The seasonal activities are highlighted, for example, in the grape harvest that can span between 5 and 10 weeks depending on the grapes involved while the daily pattern of milk production continues throughout the year even with some seasonal changes in production levels.

Another remarkable difference between rural and standard buildings concerns the indoor climate and air quality control. Wineries, dairies and creameries have traditionally been unconditioned spaces and a mixture of controlled and uncontrolled air environments. The very nature of the grape or milk delivery and some initial processing requires an interface to the outside air with its temperature, humidity and dust particles. These air spaces can be significantly different from fermentation spaces in which the emission of carbon dioxide, water vapor and volatile organic components follow a batch pattern over several days and where frequent washing of equipment leaves wet surfaces that usually dry naturally.

On the other hand, high humidity and temperature oscillations can lead to dew point condensation and undesirable mold growth in corners or wall junctions or in food containers (especially if made by wood) (Simeray et al., 2001; Ruiz De Adana et al., 2005; Ocón et al., 2011), so there is a dynamic interaction between air temperature and humidity of inside air, with building thermal dynamics and outside air temperature (Mazarrón et al., 2012; De Rosis et al., 2014; Barbaresi et al., 2017). It is this building dynamic that is necessary to understand rather than simply average conditions and the intensity of overlapping process operations that make the design of such spaces challenging.

From another view, the approval of Kyoto's protocol, the increasing awareness of the importance of environmental sustainability, and the need of reducing production costs, have driven reg- 
ulations systems, public opinion and entrepreneurs to ask for a reduction of water and energy needs of standard - as well as agricultural - buildings.

The research of environmental sustainability in the construction sector has led to accelerate the development of energy and water saving technologies. Unfortunately, their diffusion is slowed down since building design usually does not take into account the possibility to integrate or substitute the building systems, therefore interventions to improve system performances often prove to be uneconomical or substantially impossible.

Finally, several studies showed the importance of a continuous monitoring of the environmental conditions of buildings and system performance both to optimize the system efficiency and to improve the quality of products (Lang et al., 2010; Barbaresi et al., 2015; Zhou et al., 2016). Moreover, recorded data can provide useful information to check the system status. For those reasons, there is an interest in designing future facilities so that they require less energy and water intensity, and where possible offsetting the peak demand by on-site capture and storage systems. The ultimate case is a facility that can capture and store all of its water and energy requirements, enabling it to off the energy and water grids, in other words a self-sustainable facility.

This paper focuses on a pioneering case in this field, the building complex consisting of the UC Davis Winery and Jesse Jackson Building, whose design was aimed to fulfill all the above-said requirements. In particular, this paper will discuss the characteristics of the buildings and relevant equipment, focusing on their most innovative elements in the sustainability field, with reference to the creation of an integrated design approach which allowed to obtain a fully monitored, water and energy self-sustainable facility, designed for an easy system substitution.

\section{The UC Davis Winery Facility}

The UC Davis Winery facility is located in Davis (California) at the University of California Campus. It is part of the Robert Mondavi Institute and is consists of two buildings: the winery and the sustainable winery building. The winery hosts all winemaking phases, a barrel room, offices and rooms for educational activities; the sustainable winery building was created to hold the winery utility systems. These buildings and their characteristics will be highlighted in this section. Specifically, this section describes: i) the self-sustainable winery concept; ii) the winery building; iii) the Jackson sustainable winery building; iv) thermal performance and web-based tracking; v) the net-zero energy validation; vi) the monitoring system.

\section{The self-sustainable winery concept}

The winery and the Jackson building at the University of California, Davis (Figure 1) were designed to operate only on captured sunlight and rainwater for its energy and water systems. When completed, the energy system will be only from on-site solar

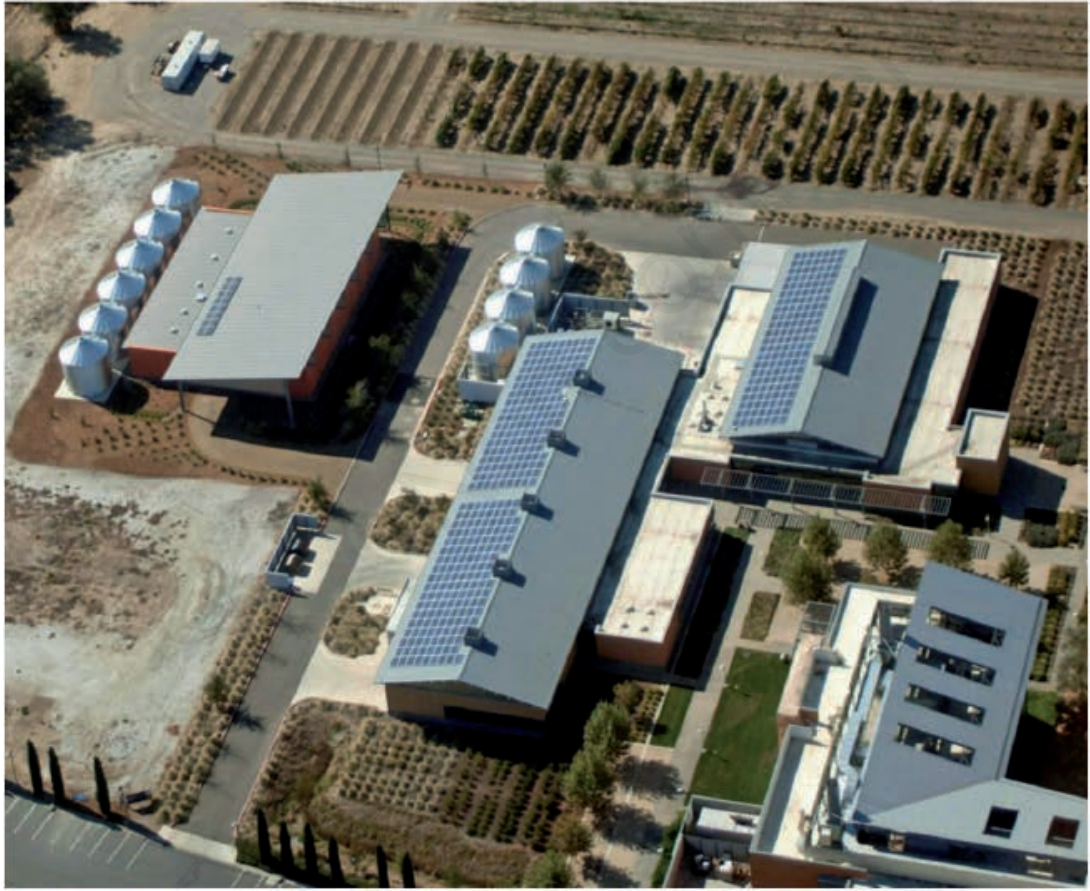

A

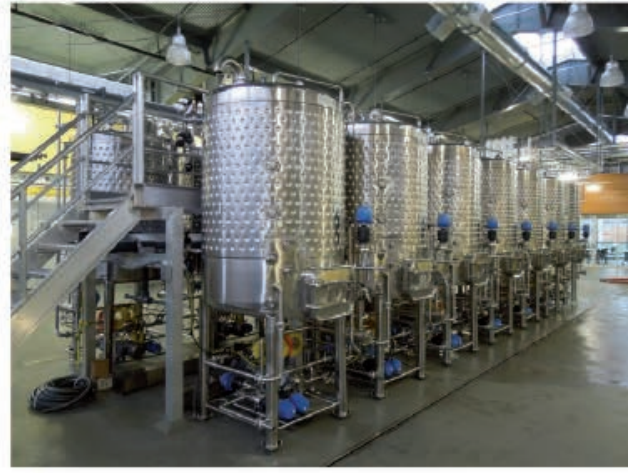

B

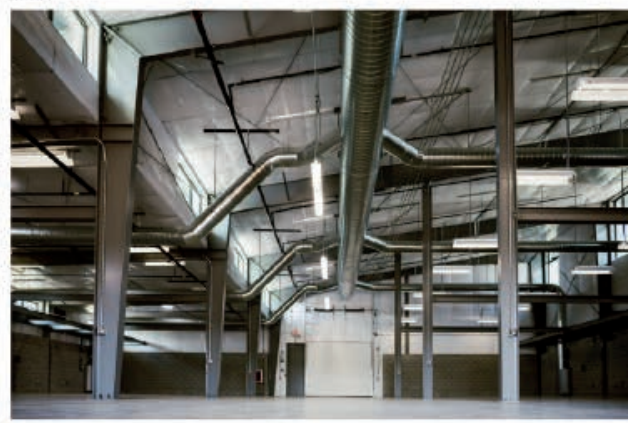

C

Figure 1. The UC Davis Winery Complex: A) Aerial view of the LEED Winery-Brewery-Food Laboratory buildings in the center, with their roof covered with solar panels and its 4 rainwater tanks, the Jackson Sustainable Winery Building, with its 8 panels and 6 rainwater tanks to the left and a section of the roof of the Robert Mondavi Institute building to the right. B) The fermentation hall of the UC Davis Winery in natural daylight. C) A view of the inside of the Jackson Building showing the air delivery duct to the floor of each bay. 
photovoltaic roof arrays with a lithium-ion battery cluster for storage. The water supply is rainwater collected from the roof of the adjacent buildings of the Robert Mondavi Institute. It is captured, filtered to remove visible matter $(50 \mu \mathrm{m})$ and stored until the major water use period between August and November. With more than six months available between its capture and its use, the rainwater is filtered into reverse osmosis water. This water is effectively sterile when produced that is free off not only microbes but also viruses and toxin chemistry. The use of rainwater from onsite capture eliminates the need for ground water or river water depletion but it is also free of any hardness or silica that would normally be left on washed surfaces after and the absence of silica means extended life time and cleaning intervals for the membranes. The cleaning solutions that are used in the winery have been changed to dilute potassium-based salts and hydrogen peroxide as the disinfectant, at ambient temperature. These solutions are captured after each washing cycle, re-filtered by nanofilter membranes, which allow the recovery of the cleaning buffers (water and slats) making $90 \%$ of it available for the next washing cycle. By operating at this level recovery there will be an $80 \%$ reduction in the volume of water required after only 10 cycles. The hot water will be produced by passive solar heating tubes and stored for several days and chilled water will be made from direct contact of water with a bed of ice chips, also stored in insulated tanks. The icemaker will operate on solar DC power and was designed to operate only during sunlight but it can be operated for longer periods when the battery pack is installed. The vapors for all fermentations are captured at the fermentor vent, then removed from the building and will eventually be sequestered as calcium carbonate, providing a zero carbon footprint to these activities. The carbonate is an easily stored and transported form of carbon that has use in the growth of algae (for biofuel production) and anaerobic bacteria cultures (for other hydrocarbon products).

The buildings were designed for the peak summer days, not monthly or annual averages. Davis has a dry and hot summer climate, with cool evening air temperatures from airflows across the nearby Sacramento River delta and San Francisco Bay. Both buildings have night air intake systems, which provides for acceptable cooling each evening rather than the use of air conditions (and its energy requirement) during the daytime.

At the time there were no solar panels on any building and no certified buildings on the UC Davis campus.

At present the reverse osmosis filtration system that filters rainwater into ultrapure water was the first system in operation. This water system is stored and used for the cleaning and sanitizing of the winery fermentors, piping and processing equipment as well as laboratory water. This unit runs two pumps, a centrifugal transfer pumps and a high-pressure filter pump and consumes $2.6 \mathrm{KW}$ when operating. The heat generation of this system is estimated to be $0.5 \mathrm{KW}$ and becomes an additional load for the air intake system to address.

\section{The winery building}

The winery building was designed to be self-sustainable in water and energy and with a zero carbon footprint. In order to be compatible with these objectives the building was designed to be a LEED Platinum facility with extensive rainwater and solar energy capture. The water requirements for the toilets and adjacent landscape are both supplied by the roof rainwater, stored in four $160 \mathrm{~m}^{3}$ galvanized tanks with a polyvinyl liner bag inside. This water is filtered to remove 50 micron and larger matter and then ozonated and stored. It is not used for drinking water, winemaking or cleaning activities. The roof is covered with 464 Canadian Solar 230P panels, which have a nominal peak production of $106 \mathrm{KW}$. This power is inverted and fed into the campus power grid, effectively taking the Winery off the grid every day during sunlight for the past 6 years and returning more energy than it draws at night time.

The design incorporated a significant daylight cupola in the roof ridge of the main fermentation hall and two offices and the laboratory have adjustable solar tube lighting in the ceiling. The fermentation hall in natural light can be seen in Figure 1B. There is an ability to see through the fermentation hall into the adjacent vineyard as well as from outside through the building.

\section{The Jackson sustainable winery building}

The Jackson sustainable winery building is designed to hold the various utility systems that will enable the winery to be selfsustainable in energy and water and able to sequester all of the carbon dioxide from fermentations. It has nine bays or open spaces for these systems and any related research projects to be installed. Figure $1 \mathrm{C}$ is a view of the interior shortly after completion.

As an unoccupied space without any offices or everyday work spaces it was not eligible to be a LEED certified building. Consideration was given to living building certifications for net zero carbon energy and water but since the systems were going to be installed in stages after the building was completed, this was not pursued. Instead, a highly passive design was specified based on previous summer heat loads and an ability to operate using only night air rather than air conditioning. This led to a tight and highly insulated building envelope that has delivered maximum daily temperature fluctuations of less than $2^{\circ} \mathrm{C}$ while able to hold the temperature anywhere between 15 and $20^{\circ} \mathrm{C}$. [These conditions similar to those of an ideal above-ground barrel or warehouse building (Mazarrón and Cañas, 2010; Barbaresi et al., 2014; Tinti et al., 2014)] The envelope includes an insulated slab, metal panels with high density polyurethane with RSI values of $10 \mathrm{BTU} \cdot \mathrm{hr}^{-1} \cdot \mathrm{F}^{-1} \cdot \mathrm{ft}^{-2}$ $\left(60 \mathrm{~W} \cdot \mathrm{m}^{-2} \cdot \mathrm{K}^{-1}\right)$ and a roof with similar panels but RSI of 13 $\mathrm{BTU} \cdot \mathrm{hr}^{-1} \cdot \mathrm{F}^{-1} \cdot \mathrm{ft}^{-2}\left(70 \mathrm{~W} \cdot \mathrm{m}^{-2} \cdot \mathrm{K}^{-1}\right)$. All insulated joints in steel section that pass through the envelope.

The eight photovoltaic panels on the roof provide more than enough energy for the night air fan operation. Additional capacity was included to allow for future system installations that would contribute to the internal heat generation. This included the fan and its ducting system so that an underground rock bed could be added for additional thermal storage that would be cooled at night and used in the day during summer and reversed for during winter. A twelve pipe manifold installed below grade connects the building to the Winery and this water loops for $\mathrm{HW}, \mathrm{CW}, \mathrm{AW}$, liquid transfer lines for CIP solutions and gas lines for $\mathrm{N}_{2}$, Compressed Air and $\mathrm{CO}_{2}$. The six $160 \mathrm{~m}^{3}$ rainwater storage tanks shade the southern wall from direct sunlight and provide a reduction in wall surface temperatures. At the time of the initial design there was space to produce on-site hydrogen by electrolysis and for a fuel cell operating on hydrogen, for night time power. This option remains open for the future.

\section{Thermal performance and web-based tracking}

The Jackson building is fitted with fourteen battery powered temperature transmitters, located in the middle of each bay, with three in the central hallway and one outside for outside air conditions. The outside transmitter is deliberately located in a position so that is in direct sunlight for part of the morning, in shade for the rest of the day and next to a window which opens as part of the night air displacement system. In this way it can demonstrate the temperature difference in direct sun and shade and show the tem- 
perature difference between inside and outside air when the fan is in operation.

The daily inside and shaded outside temperature data for a two week period in July of 2013, peak summer conditions, can be seen in Figure 2. The maximum outside air temperature varies between 30 and $39^{\circ} \mathrm{C}$ while the corresponding minimum varies between 13 and $20^{\circ} \mathrm{C}$ with an average daily air temperature of $25^{\circ} \mathrm{C}$. In contrast, the inside temperature at one location near the center of the building was always between 21 and $25^{\circ} \mathrm{C}$, with a diurnal oscillation of typically $2^{\circ} \mathrm{C}$. This is a natural attenuation of more than 10 fold. Such performance is the result of four contributions (explained in detail in the previous paragraph The Jackson sustainable winery building): i) the envelope insulation (reducing the conduction heat transfer); ii) the building tightness (reducing the convection heat transfer); iii) the specifically designed roof overhangs (reducing the radiation heat transfer); iv) the night ventilation (taking advantage of outdoor environment when favorable).

Note that the fan intake could have been continued to bring the building back down to $20^{\circ} \mathrm{C}$ every night and down to $15^{\circ} \mathrm{C}$ twelve of the sixteen days of the observation period. The fan control during this period was simply a timed operation for $30 \mathrm{~min}$ at midnight, not an optimized control based on choosing the minimum outside air temperature and without any strategy based on expected heat events.

The temperature data are transferred to a cloud-based PI system (OSISoft) and can be retrieved on a website and handheld devices through the PI Coresight application. These data will be shared with other researchers interested in building dynamics and performance as a model building, eventually on a public website. A 3D model of this building has been developed by the Agricultural Engineering group at the Department of Agricultural Sciences of the University of Bologna (Italy), thus providing a reference for future studies in the wider research about new criteria of winery design (Barbaresi et al., 2017). It will eventually serve as a reference building whose daily performance can be assessed at any of several locations throughout the world, using local climate information.

\section{Net zero energy validation}

The design objective was to make the building at least net zero in energy on a daily and annual basis. Eight panels (SunPower SPR $327-N E-W H T-D)$ with a maximum power of $327 \mathrm{~W}$ and a panel efficiency of $20.1 \%$ are located on the sloping roof (12 degrees). The outside air fan was a $1.1 \mathrm{~kW}(1.5 \mathrm{hp})$ operating at $480 \mathrm{VAC}$ and drawing $2.83 \mathrm{~m}^{3} \mathrm{~s}^{-1}(6000 \mathrm{CFM})$ of air. The expected heat load from the fan, which is located in the building, is $280 \mathrm{~W}$.

The collection of solar energy generation and fan energy use were monitored during the first year after construction to understand the empty building performance. This showed that 6.662 MWh were generated and 3.56 MWh were consumed, confirming its energy positive design performance and a consumption of 4.45 $\mathrm{KWhm}^{-2}$. The latitude of Davis is at $38.536 \mathrm{~N}$ and it has a midwinter day length of $9.35 \mathrm{~h}$ and a mid-summer day length of 14.67 h. In this first year of testing, the rainwater tanks that now shade the south wall were not in place making the heat gain higher than normal due to direct sunlight and higher surface temperature during the day.

The tightness of the building envelope was evaluated by measuring the leakage rate at $50 \mathrm{~Pa}$ differential pressure, which can be expressed in terms of the open area per unit surface area as 3.5 $\mathrm{mm}^{2} \mathrm{~m}^{-2}\left(0.0005 \mathrm{in}^{2} \mathrm{ft}^{-2}\right)$. The blower door test gave an $\mathrm{N}$ value of 17.2, which corresponds to 0.72 air changes per hour, close to the Passivhaus standard of 0.6 .

\section{Monitoring system}

A web-based network of 3 wineries (A, B and C) and 2 Creamery locations was established using small battery-powered multisensory boxes, suitable for wash-down environments. The sensor boxes were placed in different production areas to monitor the variation the air environment at 15 min intervals. A typical sensor box is shown in Figure 3A.

The measurements of temperature, relative humidity, carbon dioxide, volatile organic components and dust particles in production spaces and outside air were accomplished with fabricated circuit boards with a wireless antenna. The boxes formed a local network with a central powered box export the data. The information was accessible web site, on large format display screens and on hand-held phone displays, globally.

Winery A was built in 1990, located in the Sonoma County of northern California. It is a one level, metal building on a concrete

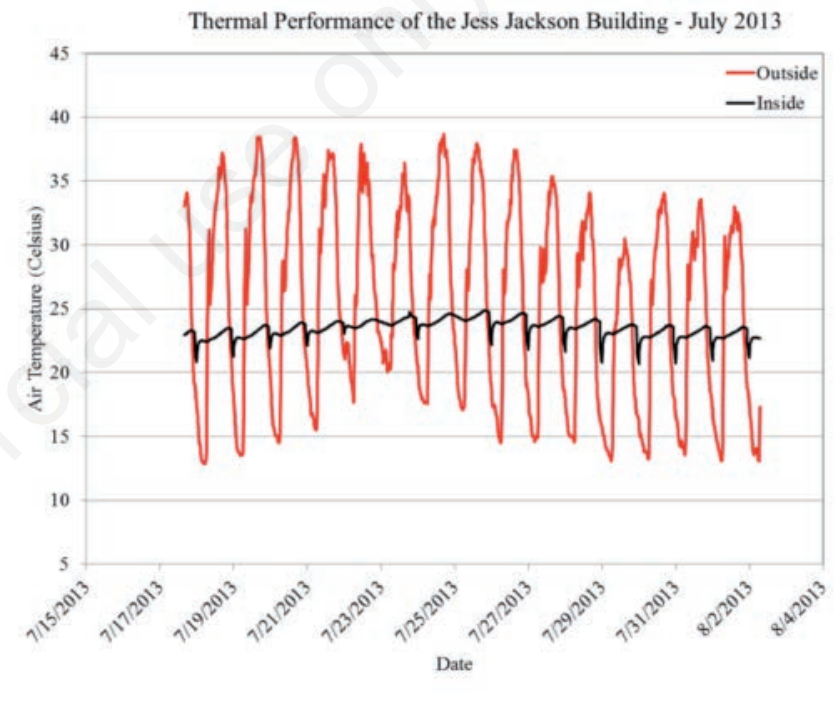

Figure 2. The daily air temperature patterns in a two-week period in July 2013.

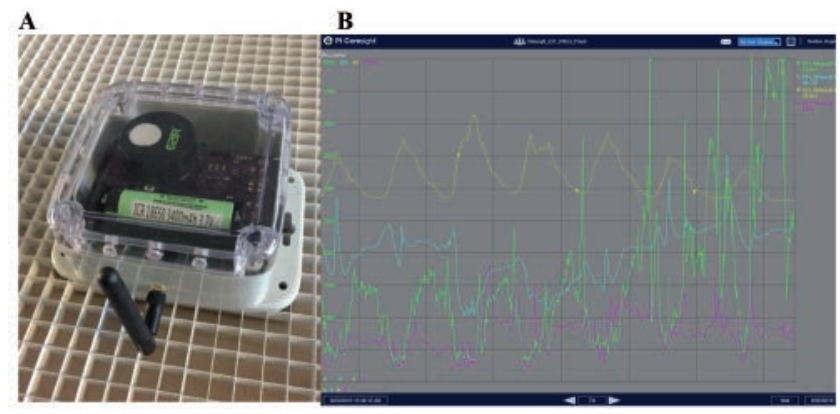

Figure 3. A) A wireless, waterproof battery-powered sensor box for the measurement of temperature, humidity and carbon dioxide in winery and creamery production rooms. B) The air environment in the fermentation hall of a commercial winery during a week of the 2016 harvest. The air temperature (yellow), humidity (aqua), carbon dioxide (green) and volatile organic compounds (purple). Note the progression of the carbon dioxide levels in the first days of the harvest period when the building is closed up at night. 
slab with, producing both red and white wines, with separate red wine and white wine barrel rooms and an outside area for crush and press operations. It has a laboratory adjacent to the fermentation hall. It has a tasting room but does not offer tours to visitors.

Winery B was built in 1988, located in the Napa County of northern California. It has two levels, produces only red wine, with spate barrel rooms for the first and second year of aging. It conducts grape receival and destemming on the first floor, indoors, with the fermentation hall on the ground floor below. It conducts several tours daily of small groups, even during harvest.

This facility has delivery door, which are open to the outside air during the day and closed up at night. The yellow trace in Figure 3B shows this daily pattern. The production floor is washed at the end of each day and this is reflected in a rise in humidity and the accumulation of carbon dioxide when the building is closed up. Even with exhaust fans that are activated by carbon dioxide sensors, the air intake is restricted when the building is closed. The ambient levels rise to approach unsafe levels for brief periods each morning.

Winery C is the UCD winery, which was built in 2010 and is located on UC Davis campus. It has both teaching and research activities using its $200 \mathrm{~L}$ and $2000 \mathrm{~L}$ fermentors, usually at the same time. It has outside covered grape delivery, crushing and pressing, area and a laboratory. It has some tour groups during harvest but also has three lab sections of 20 students in the winemaking class each week. It has an adjacent classroom, a small barrel room and bottled wine storage rooms. It is unique in that the fermentation vapors are collected at each fermentor rather than emitted into the air. As can be seen in Figure 4, carbon dioxide levels range between 500 and $1200 \mathrm{ppm}$, well below the code requirement of $5000 \mathrm{ppm}$.

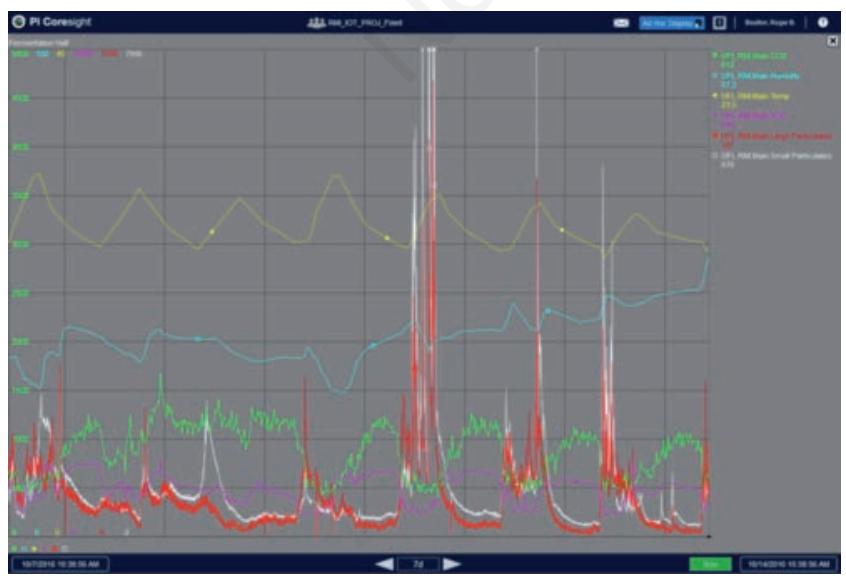

Figure 4. A week of the air temperature (yellow), humidity (aqua), carbon dioxide (green), volatile organic compounds (purple) and large (red and small (white) particle counts in the fermentation hall at the UC Davis Winery during the 2016 harvest.

\section{Conclusions}

The UC Davis winery complex was designed to be a water and energy self-sustainable facility, to address the following challenges: i) meeting the specificity of food processing buildings compared to standard constructions; ii) meeting the peculiar needs of winemaking in terms of air quality and indoor climate conditions; iii) coping with water scarcity in California.

Moreover, particular attention has been dedicated to indoor natural lighting, carbon dioxide sequestration, possibility to easily substitute or integrate existing systems with high performance ones.

The winery was certified LEED Platinum, obtaining both Water, Indoor Environment Quality, and Innovation and Design points, and 60 out of 69 points under the version 2.2 scorecard. It has been ranked in the top 3\% of all LEED Platinum buildings completed at that time, and was the first to be self-sustainable in both water and energy.

In 2016, the UC Davis campus was ranked first in sustainability among over 500 universities throughout the world. The features of the UC Davis campus that distinguish it from many of the others in the top ten, are the number of green certified buildings and the extent of solar PV power for reduced carbon footprints. Both of these features were pioneered on the campus by our winery and Jackson buildings.

Finally, a remote monitoring system has been installed in this building as well as in other 4 University food-processing buildings. The dynamics of air environments in several rooms of commercial winery and creamery sites are presented which show the variation between the daily patterns and the differences between rooms. This wireless network extends over locations more than $100 \mathrm{~km}$ away and can be seen on handheld devices in real time. The monitoring system allows a continuous check on the usage and efficiency of the winery and its systems. It can also be used as reference for other wineries or food processing buildings.

Under this point of view the winery aims to be a first example of a new building design conception, oriented to efficiency and self-sustainability.

\section{References}

Barbaresi A., Dallacasa F., Torreggiani D., Tassinari P. 2017. Retrofit interventions in non-conditioned rooms: calibration of an assessment method on a farm winery. J. Build. Perform. Simulat. 10:91-104.

Barbaresi A., Torreggiani D., Benni S., Tassinari P. 2014. Underground cellar thermal simulation: definition of a method for modelling performance assessment based on experimental calibration. Energ. Build. 76:363-72.

Barbaresi A., Torreggiani D., Benni S., Tassinari P. 2015. Indoor air temperature monitoring: a method lending support to management and design tested on a wine-aging room. Build. Environ. 86:203-10.

Boulton R.B., Singleton V.L., Bisson L.F., Kunkee R.E. 1998. Principles and practices of winemaking. Springer, New York, NY, USA.

De Rosis A., Barbaresi A., Torreggiani D., Benni S., Tassinari P. 2014. Numerical simulations of the airflows in a wine-aging room: a lattice Boltzmann-immersed boundary study. Comput. Electron. Agricult. 109:261-70.

Lang C., Hübert T., Quaas H., Linke M. 2010. On-line measurement of 
humidity in the agri-food chain. Acta Hortic. 858:413-7.

Mazarrón F.R., Cañas I. 2010. Traditional underground wine cellars of Spain: building and morphological properties and hygrothermal behaviour - taking advantage of soil properties. Build. Environ. 97:235-52.

Mazarrón F., Cid-Falceto J., Cañas Guerrero I. 2012. An assessment of using ground thermal inertia as passive thermal technique in the wine industry around the world. Appl. Thermal Engine. 33-34:54-61.

Ocón E., Gutiérrez R., Garijo P., Santamaría P., López R., Olarte C., Sanz S. 2011. Factors of influence in the distribution of mold in the air in a wine cellar. J. Food Sci. 76:M169-74.

Ruiz De Adana M., Lopez L.M., Sala J.M. 2005. A fickian model for calculating wine losses from oak casks depending on con- ditions in ageing facilities. Appl. Thermal Engine. 25:709-18. Simeray J., Mandin D., Mercier M., Chaumont J.P. 2001. Survey of viable airborne fungal propagules in French wine cellars. Aerobiologia 17:19-24.

Tinti F., Barbaresi A., Benni S., Torreggiani D., Bruno R., Tassinari P. 2014. Experimental analysis of shallow underground temperature for the assessment of energy efficiency potential of underground wine cellars. Energ. Build. 80:451-60.

Zhou H., Han K., Wei X. 2016. Research on and realization of interactive wireless monitoring and management system of processed grain based on Web3D. In: Proceedings - 2015 International Conference on Industrial Informatics Computing Technology, Intelligent Technology, Industrial Information Integration, ICIICII 2015. 